\title{
Effect of VDRA on survival in incident hemodialysis patients: results of the FARO-2 observational study
}

Piergiorgio Messa ${ }^{1 *}$, Mario Cozzolino ${ }^{2}$, Diego Brancaccio ${ }^{3}$, Giuseppe Cannella $^{4}$, Fabio Malberti ${ }^{5}$, Anna Maria Costanzo ${ }^{6}$, Umberto di Luzio Paparatti ${ }^{6}$, Vincenzo Festa ${ }^{6}$, Giuliana Gualberti ${ }^{6}$, Sandro Mazzaferro ${ }^{7}$ and on behalf of the FARO Study Group

\begin{abstract}
Background: Mortality rate among patients with stage five chronic kidney disease (CKD) maintained on hemodialysis (HD) is high. Although evidence suggests that use of Vitamin D Receptor Activators (VDRA) in CKD patients increases survival, few studies have examined the effect of VDRA in incident HD patients. The FARO-2 study evaluated the clinical outcome of VDRA therapy on mortality in incident HD patients.

Methods: FARO-2 was a longitudinal epidemiological study performed on 568 incident HD patients followed prospectively from 26 dialysis centers over a 3-year period. Data were collected every 6 months using a questionnaire, obtaining clinical, biochemical and therapeutic parameters. Kaplan-Meier curves and Cox proportional hazard regression models were used to determine cumulative probability of time-to-death and adjusted hazard ratios.

Results: 568 patients (68\% male) with an average age of 65.5 years were followed up. Mean dialysis duration at study entry was 3 months. VDRA use increased from $46 \%$ at 6 months to $54.7 \%$ at 36 months of follow-up $(p=0.08)$. No difference was observed in the presence of comorbid diseases at baseline in patients with and without VDRA therapy. Cumulative probability of survival at 24 months was $74.5 \%$ (95\% Cl: 70.2-78.3). Patients receiving VDRA therapy showed a significant increase in survival at 24 months (80.7\%; 95\% Cl: 75.7-84.8) compared to those without $(63.3 \% ; 95 \% \mathrm{Cl}: 54.8-70.7, \mathrm{p}<0.01)$. The presence of vascular disease, decreased hemoglobin, increased $P$ and lack of VDRA treatment were significantly associated with an increased risk of mortality. Lack of VDRA treatment still remained significant as a predictor of mortality after adjusting for levels of PTH, $\mathrm{P}$ and Ca $(\mathrm{HR}=2.16,95 \% \mathrm{Cl}: 1.09-4.30, \mathrm{p}=0.03)$.
\end{abstract}

Conclusions: Findings from FARO-2 indicate that in incident HD patients VDRA therapy was associated with increased survival.

Keywords: PTH, Calcitriol, Paricalcitol, Hemodialysis, CKD-MBD

\section{Background}

Mortality rates among chronic kidney disease (CKD) patients undergoing hemodialysis (HD) is high and exceeds those not undergoing HD [1,2]. The main cause of dialysis related mortality has largely been attributed to cardiovascular disease [2]. CKD patients are also affected by mineral and bone disorders (CKD-MBD), resulting in

\footnotetext{
* Correspondence: pmessa@policlinico.mi.it

'Nephrology, Dialysis and renal Transplant, Fondazione Ca' Granda IRCCS-Policlinico, Milan, Italy

Full list of author information is available at the end of the article
}

abnormalities in serum calcium $(\mathrm{Ca})$, phosphorous $(\mathrm{P})$ and parathyroid hormone (PTH). Changes in mineral metabolism have also been associated with higher rates of both allcause and cardiovascular-related mortality [3-15]. The majority of $\mathrm{HD}$ patients are also deficient in the endogenous hormone, 1,25-dihydroxyvitamin D (calcitriol) [16]. The reduction in calcitriol levels, which are a well known causal factor in the pathogenesis of secondary hyperparathyroidism (SHPT) [17], has also been associated with the poor clinical outcomes of these patients [18].

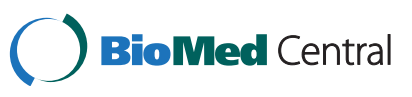

(c) 2015 Messa et al.; licensee BioMed Central. This is an Open Access article distributed under the terms of the Creative Commons Attribution License (http://creativecommons.org/licenses/by/4.0), which permits unrestricted use, distribution, and reproduction in any medium, provided the original work is properly credited. The Creative Commons Public Domain Dedication waiver (http://creativecommons.org/publicdomain/zero/1.0/) applies to the data made available in this article, unless otherwise stated. 
However, the exogenous administration of calcitriol and other vitamin D metabolites may result in hypercalcaemia, potentially contributing to increase the risk of morbidity and mortality $[19,20]$. To overcome this problem, several synthetic vitamin D receptor activators (VDRAs) have been developed, that are less hypercalcemic and hyperphosphataemic and are efficacious in treating patients with CKD-MBD, [21,22] and as such, are now considered the standard therapy for patients with CKD [23]. In fact, the occurrence of hypercalcemia and hyperphosphatemia is more frequent during calcitriol treatment than with the use of a selective VDRA (paricalcitol), possibly due to a lesser bone resorption and intestinal absorption of these metabolites $[24,25]$. This may translate into reduced risk of vascular calcifications and hence cardiovascular events. The use of VDRAs, such as calcitriol or the selective VDR activator paricalcitol, is associated with improved survival in HD patients [15,26-32]. It is also recognized that the majority of these retrospective survival studies was performed on prevalent chronic HD patients and it is known that prolonged dialysis is an independent significant predictor of death [33]. To date, only few and small cohort studies have examined the effect of VDRA therapy on survival in incident HD patients. The original FARO study was the first epidemiological study that evaluated SHPT management and survival in HD patients in Italy [32,34]. The aim of the FARO-2 cohort, a sub-group of the original FARO study, was to assess SHPT management and alignment with K-DOQI target ranges, [35,36] and to specifically evaluate the clinical outcome of VDRA therapy on mortality in incident HD patients, using time-dependent Cox models.

\section{Methods}

\section{Study design}

The FARO-2 study was a multicentric epidemiological study performed on a subgroup of patients who initiated the HD therapy over the course of the FARO study (conducted between 2006 and 2007) [32,34]. FARO-2 was undertaken in 26 dialysis centers in Italy. Data collection was retrospective, involving the completion of another two questionnaires for the year of 2008 (added to the previous 4 questionnaires collected during FARO study for the years 2006 and 2007). The physician attending the dialysis procedure completed the clinical and laboratory parameter questions on the dedicated questionnaire for each patient. Final data review and approval were completed by the primary investigator at the study site. Additional information on specific parameters included in the survey has been previously described [34]. All subjects who started dialysis treatment during the FARO study and all subjects at the time of the $1^{\text {st }}$ survey of the FARO Study (April 2006) that had a dialysis vintage of $\leq 8$ months were included. Data are presented by semester from the beginning of dialysis (irrespective of the moment in which the patient entered into the FARO study). The follow up period for each subject is variable and ranged from a minimum of 6 months to a maximum of 3 years. All patients provided written informed consent and the study was approved by all local Ethic Committees.

\section{VDRA treatment}

For patients with stage 5 CKD undergoing HD, the 2003 guidelines of the Kidney Disease Outcomes Quality Initiative (KDOQI) of the National Kidney Foundation were used [35]. According to these guidelines, target ranges for these patients for iPTH concentrations were 150-300 pg/ $\mathrm{mL}$ and VDRA therapy was only administered to HD patients with iPTH $>300 \mathrm{pg} / \mathrm{ml}$. FARO2 was an observational study, therefore medication was administered at the discretion of the treating physician, according to Italian guidelines.

\section{Statistical analysis}

Descriptive statistics of categorical data are presented as summary tables reporting frequencies and percentages, while quantitative variables such as KDOQI parameters were summarized using medians and interquartile ranges. Comparisons between two groups of categorical variables were analyzed by chi-squared tests. Differences in the proportion of patients receiving VDRA therapy over the study period were assessed by chi-squared for trend. Differences for KDOQI parameters were evaluated using Kruskal-Wallis test.

Risk of all-cause mortality was assessed standard survival techniques such as Kaplan-Meier curves to estimate the cumulative probability of death. In particular, an extended Kaplan-Meier survival plot was also performed to assess the effect of VDRA therapy (i.e., untreated vs. oral/ intravenous (IV) calcitriol or IV paricalcitol) on all-cause mortality as previously described [15,32]. In brief, those patients not receiving VDRA therapy for the entire followup period were always considered as untreated; for those who started VDRA therapy, the risk time for each patient was divided into specific time contributions depending on when treatment started. Before treatment started, the specific time contribution was for the untreated group. As an-intention-to-treat analysis when a patient interrupted or discontinued VDRA they were still considered in the VDRA group. Two multiple time dependent Cox proportional hazard regression models were performed to estimate adjusted HRs (with 95\% confidence intervals (95\% $\mathrm{CI})$. The first model included various demographic and clinical covariates, including age (per 10-year increase), gender, comorbidities (i.e., hypertension: yes vs. no; dyslipidemia: yes vs. no; heart disease: yes vs. no; neoplasias: yes vs. no; liver disease: yes vs. no; vascular disease: yes vs. no; treatment of diabetes: yes vs. no; haemoglobin (per $1 \mathrm{~g} / \mathrm{dl}$ 
increase); albumin (per $1 \mathrm{~g} / \mathrm{dl}$ increase), VDRA use (untreated vs. treated), calcium-based phosphate binder use (no vs. yes) and non-calcium-based phosphate binder use (no vs. yes). The second model, together with the previously described variables, also included the serum phosphorus ( $\leq 3.5$ vs. $>3.5$ to $5.5 ;>5.5$ vs. $>3.5$ to $5.5 \mathrm{mg} / \mathrm{dL}$ ), serum calcium ( $\leq 8.4$ vs. $>8.4$ to 9.5 ; $>9.5$ to 10.5 vs. $>8.4$ to $9.5 ;>10.5$ vs. $>8.4$ to $9.5 \mathrm{mg} / \mathrm{dL}$ ), parathyroid hormone $[(\mathrm{PTH}) \leq 150$ vs. 150 to $300 ;>300$ vs 150 to $300 \mathrm{pg} / \mathrm{ml}]$. All parameters were included as time changing variables except age and gender. Patients who moved or were transferred to other dialysis centers or who were lost to followup were censored as alive at the last visit performed. To prevent possible non-proportionality of risks among clinical centers, Cox proportional hazard regression models were stratified by clinical center [37]. A $p$-value of $<0.05$ was considered statistically significant. Statistical analysis was performed using SAS (version 9.2 for WindowsTM, Cary, NC) and STATA (version 12.0, College Station, TX) software.

\section{Results}

Disposition and baseline clinical characteristics

Patient demographic and clinical characteristics are summarized in Table 1. The proportion of males was higher Table 1 Baseline clinical characteristics in patients with
and without VDRA therapy

\begin{tabular}{|c|c|c|c|c|}
\hline \multirow{2}{*}{$\begin{array}{l}\text { Clinical } \\
\text { characteristic }\end{array}$} & \multirow[t]{2}{*}{ Total } & \multicolumn{2}{|l|}{ VDRA } & \multirow{2}{*}{$\begin{array}{l}\text { P- } \\
\text { value }\end{array}$} \\
\hline & & Yes & No & \\
\hline \multicolumn{5}{|l|}{ General } \\
\hline N (\%) & 568 & $389(68.5)$ & 179 (31.5) & \\
\hline $\begin{array}{l}\text { Gender (male), } \\
\text { n (\%) }\end{array}$ & 389 (68.5) & $260(66.9)$ & $129(72.1)$ & \\
\hline $\begin{array}{l}\text { Median age } \\
(\mathrm{IQR}) \text {, years }\end{array}$ & $70(57-77)$ & $69(56-76.5)$ & $70(60-77)$ & 0.31 \\
\hline $\begin{array}{l}\text { Median height } \\
(\mathrm{QQR}), \mathrm{cn}\end{array}$ & $165(160-170)$ & $165(160-171)$ & $167(160-170)$ & 0.89 \\
\hline $\mathrm{BMI}\left(\mathrm{Kg} / \mathrm{M}^{2}\right)$ & $23.5(21.2-26.4)$ & $23.5(21.2-26.3)$ & $23.4(20.8-26.5)$ & 0.47 \\
\hline \multicolumn{5}{|l|}{$\begin{array}{l}\text { Comorbid } \\
\text { diseases }\end{array}$} \\
\hline $\begin{array}{l}\text { Hypertension, } \\
\text { n (\%) }\end{array}$ & $496(87.3)$ & 347 (89.2) & $149(83.2)$ & 0.05 \\
\hline $\begin{array}{l}\text { Cardiovascular } \\
\text { disease, n (\%) }\end{array}$ & $338(59.5)$ & $233(59.9)$ & $105(58.7)$ & 0.78 \\
\hline $\begin{array}{l}\text { Vascular disease, } \\
\text { n (\%) }\end{array}$ & $277(48.8)$ & $188(48.3)$ & 89 (49.7) & 0.6 \\
\hline Diabetes, n (\%) & $164(28.9)$ & $109(28)$ & $55(30.7)$ & 0.52 \\
\hline $\begin{array}{l}\text { Dyslipidemia, } \\
\text { n (\%) }\end{array}$ & $104(18.3)$ & $164(42.2)$ & $61(34.1)$ & 0.07 \\
\hline $\begin{array}{l}\text { Liver disease, } \\
\text { n (\%) }\end{array}$ & $54(9.5)$ & $42(10.8)$ & $12(6.7)$ & 0.12 \\
\hline
\end{tabular}

$\mathrm{BMI}=$ body mass index.

$\mathrm{IQR}=$ interquartile range.

Statistically significant $\mathrm{p}$-values are highlighted in bold.
(68.5\%) than females (31.5\%). At the start of dialysis, the median age was 70 years for both women and men. The frequency of dialysis sessions was 3 times per week for $83.1 \%$ of subjects, twice a week for $12.32 \%$ of subjects, once a week for $4.05 \%$ of subjects. A small proportion of subjects $(0.18 \%)$ also had dialysis $>3$ times per week. Most frequent comorbid diseases included hypertension (77\%), ventricular hypertrophy (55.3\%) and cardiovascular disease (39.8\%). Clinical characteristics remained the same for patients receiving VDRA therapy compared to those without VDRA therapy (Table 1). Furthermore, the presence of comorbid diseases at baseline was similar between

Table 2 Time-dependent characteristics in patients with and without VDRA therapy

\begin{tabular}{|c|c|c|c|c|c|}
\hline Characteristic & $\begin{array}{l}\text { Follow-up } \\
\text { time (months) }\end{array}$ & Total & VDRA & No VDRA & p-value \\
\hline \multirow{6}{*}{$\begin{array}{l}\text { Serum calcium } \\
(\mathrm{mg} / \mathrm{dl})\end{array}$} & 6 & 8.8 & 8.8 & 8.8 & 0.34 \\
\hline & 12 & 8.9 & 8.9 & 8.8 & 0.02 \\
\hline & 18 & 8.9 & 8.9 & 8.8 & 0.26 \\
\hline & 24 & 9.0 & 9.0 & 9.0 & 0.2 \\
\hline & 30 & 9.0 & 8.9 & 8.9 & 0.85 \\
\hline & 36 & 8.9 & 8.9 & 9.0 & 0.11 \\
\hline \multirow{6}{*}{$\begin{array}{l}\text { Serum phosphorus } \\
(\mathrm{mg} / \mathrm{dl})\end{array}$} & 6 & 5.1 & 5.0 & 5.2 & 0.17 \\
\hline & 12 & 5.2 & 5.2 & 5.3 & 0.29 \\
\hline & 18 & 5.0 & 5.0 & 5.1 & 0.44 \\
\hline & 24 & 4.9 & 4.9 & 4.9 & 0.93 \\
\hline & 30 & 4.9 & 4.9 & 4.9 & 0.56 \\
\hline & 36 & 4.8 & 4.8 & 4.8 & 0.49 \\
\hline \multirow[t]{6}{*}{ PTH (pg/ml) } & 6 & 225 & 313 & 157 & $<0.01$ \\
\hline & 12 & 197 & 245 & 141.3 & $<0.01$ \\
\hline & 18 & 201 & 227 & 155 & $<0.01$ \\
\hline & 24 & 212 & 240.3 & 155 & $<0.01$ \\
\hline & 30 & 247 & 268.3 & 148.5 & $<0.01$ \\
\hline & 36 & 254 & 260 & 197.5 & 0.15 \\
\hline \multirow{6}{*}{$\begin{array}{l}\text { Serum albumin } \\
(\mathrm{g} / \mathrm{dl})\end{array}$} & 6 & 3.60 & 3.55 & 3.55 & 0.09 \\
\hline & 12 & 3.70 & 3.70 & 3.60 & 0.03 \\
\hline & 18 & 3.75 & 3.78 & 3.70 & 0.19 \\
\hline & 24 & 3.76 & 3.80 & 3.69 & 0.06 \\
\hline & 30 & 3.74 & 3.76 & 3.73 & 0.51 \\
\hline & 36 & 3.80 & 3.72 & 3.81 & 0.42 \\
\hline \multirow[t]{6}{*}{ Hemoglobin (g/dl) } & 6 & 10.9 & 11.0 & 10.9 & 0.08 \\
\hline & 12 & 11.4 & 11.4 & 11.5 & 0.79 \\
\hline & 18 & 11.5 & 11.4 & 11.5 & 0.86 \\
\hline & 24 & 11.3 & 11.2 & 11.5 & 0.05 \\
\hline & 30 & 11.2 & 11.2 & 11.3 & 0.23 \\
\hline & 36 & 11.7 & 11.4 & 11.9 & 0.07 \\
\hline
\end{tabular}

PTH = parathyroid hormone. P-values denote comparisons between VDRA and no VDRA groups. Statistically significant $p$-values are highlighted in bold. 
the VDRA-treated group $(66.9 \%$ male; median age 70 years) and non-VDRA treated group $(72.1 \%$ male; median age 70 years) (Table 1). Although a higher proportion of VDRA-treated patients had hypertension (89.2 with VDRA vs. 83.2 without VDRA, $\mathrm{p}=0.05$ ), this difference was not deemed clinically significant. Of the 610 subjects who were considered eligible for participation in the FARO-2 study, 7 subjects were excluded because they were referred to 2 centers that did not adhere to the project while 35 were excluded because, on closer scrutiny, had a dialysis start date earlier than 8 months of the date of study enrollment, therefore not meeting the inclusion criteria. The total sample size was 568 subjects. The number of evaluable patients changed from the $1^{\text {st }}$ survey (128 evaluable patients with a follow-up of 3 years) to the $6^{\text {th }}$ survey (568 evaluable patients with a follow-up of 6 months).

Levels of PTH, Ca and P at baseline and follow-up Levels of serum PTH (median values at 6 months vs 36 months; 225 vs $254 \mathrm{pg} / \mathrm{ml}), \mathrm{Ca}(8.8 \mathrm{vs} 8.9 \mathrm{~g} / \mathrm{dl})$ and P (5.1 vs $4.8 \mathrm{mg} / \mathrm{dl}$ ) for all patients did not differ significantly from baseline (Table 2). Although median serum PTH levels were significantly different in patients with VDRA compared to those without VDRA therapy (approximately $40 \%$ higher in VDRA treated patients), no marked difference was observed for other biochemical (serum calcium

Table 3 Concomitant therapy in patients over the followup period

\begin{tabular}{|c|c|c|c|c|c|}
\hline \multirow[b]{2}{*}{ Treatment } & \multirow[t]{2}{*}{ Follow-up time (months) } & \multicolumn{2}{|l|}{ Yes } & \multicolumn{2}{|l|}{ No } \\
\hline & & $\mathbf{N}$ & $\%$ & $\mathbf{N}$ & $\%$ \\
\hline \multirow[t]{6}{*}{ VDRA } & 6 & 261 & 46 & 307 & 54.0 \\
\hline & 12 & 328 & 57.8 & 239 & 42.2 \\
\hline & 18 & 335 & 67.5 & 161 & 32.5 \\
\hline & 24 & 254 & 74.1 & 89 & 25.9 \\
\hline & 30 & 162 & 75.7 & 52 & 24.3 \\
\hline & 36 & 99 & 77.3 & 29 & 22.7 \\
\hline \multirow{6}{*}{$\begin{array}{l}\text { Non-calcium-based } \\
\text { phosphate binders }\end{array}$} & 6 & 223 & 39.3 & 345 & 60.7 \\
\hline & 12 & 300 & 52.9 & 267 & 47.1 \\
\hline & 18 & 296 & 59.7 & 200 & 40.3 \\
\hline & 24 & 222 & 64.7 & 121 & 35.3 \\
\hline & 30 & 147 & 68.7 & 67 & 31.3 \\
\hline & 36 & 90 & 70.3 & 38 & 29.7 \\
\hline \multirow{6}{*}{$\begin{array}{l}\text { Calcium-based } \\
\text { phosphate binders }\end{array}$} & 6 & 302 & 53.2 & 266 & 46.8 \\
\hline & 12 & 354 & 62.4 & 213 & 37.6 \\
\hline & 18 & 339 & 68.3 & 157 & 31.7 \\
\hline & 24 & 250 & 72.9 & 93 & 27.1 \\
\hline & 30 & 161 & 75.2 & 53 & 24.8 \\
\hline & 36 & 97 & 75.8 & 31 & 24.2 \\
\hline
\end{tabular}

and serum phosphorus) and laboratory parameters (serum albumin and hemogobin) (Table 2).

\section{Use of VDRA}

389 (68.5\%) patients received VDRA therapy at least once during the follow up period and 191 (49.1\%) were taken off VDRA(even for a single visit). From the beginning of the study, there was an increase in the use of VDRA from $46 \%$ at 6 months to $54.7 \%$ at 36 months follow-up, although this increase was not statistically significant $(p=0.08$; Figure $1 \mathrm{~A})$ (Table 3). Sub-analysis of patients who received VDRA therapy revealed a significant decrease in the use of orally administered calcitriol (68.5\% at 6 month follow-up vs. $58 \%$ at 36 month follow-up, $\mathrm{p}=0.039$ ) and, concomitantly, a significant increase in the use of paricalcitol (IV) $(20.9 \%$ at 6 months to $33.3 \%$ at 36 months, $\mathrm{p}=0.045$ ) was observed between baseline and follow up (Figure 1B). Use of calcitriol

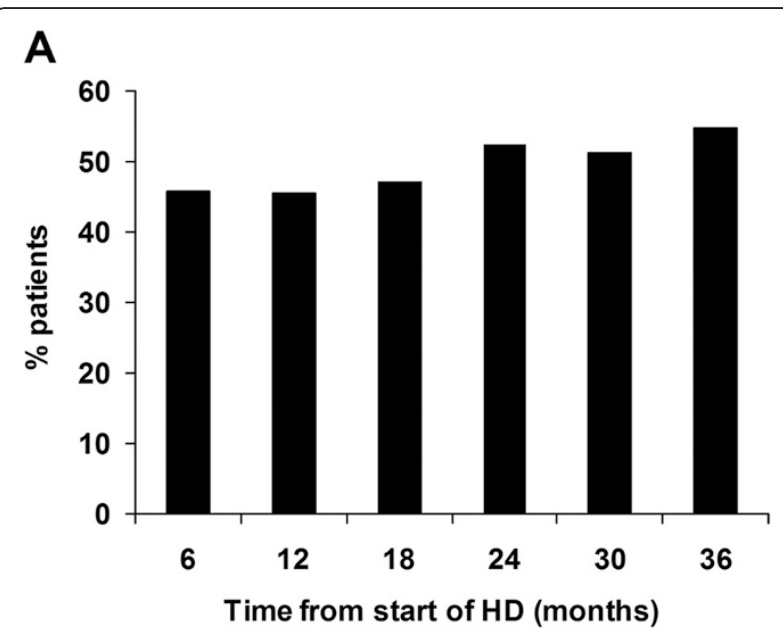

B

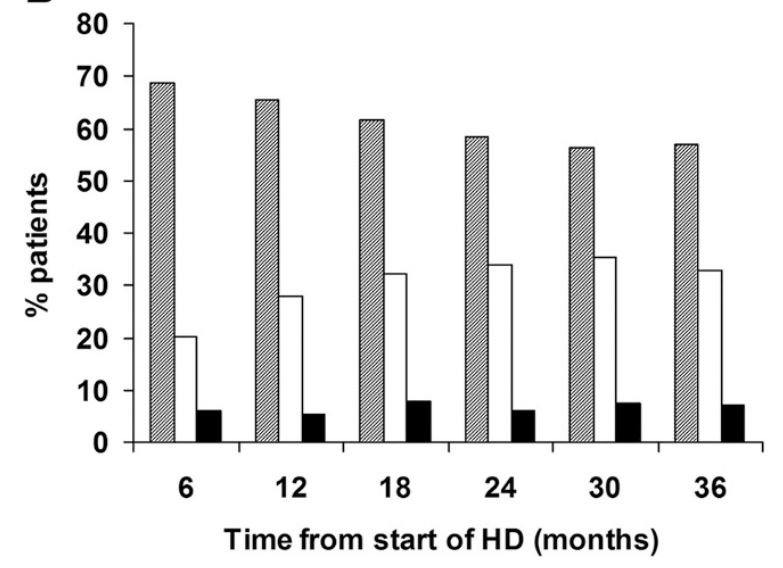

Figure 1 Proportion of patients receiving VDRA therapy. A) Proportion of patients receiving any form of VDRA. B) Proportion of patients receiving the following various forms of VDRA: oral calcitriol (hatched bars); intravenous paricalcitol (open bars) and intravenous calcitriol (filled bars). Asterix denote statistical significance between 6 and 36 month time points where ${ }^{*}=p<0.05$. 
(IV) was only in a small proportion of patients $(<10 \%)$ and did not change over the study period (Figure 1B).

\section{Concomitant medication}

In addition to VDRA use, patients received concomitant medication. At baseline the majority of patients $(\sim 70 \%)$ received iron supplementation, followed by calcium carbonate ( 50\%), other phosphate binders $(\sim 30 \%)$ and insulin $(\sim 20 \%)$. The proportion of patients receiving medication changed over the study period (Table 3 ). The proportion of patients receiving non-calcium-based phosphate binders and calcium-based phosphate binders increased from $39.3 \%$ at 6 months to $70.3 \%$ at 36 months and $53.2 \%$ at 6 months to $75.8 \%$ at 36 months respectively (Table 3 ). While the proportion of patients receiving the phosphate binder sevelamer $\mathrm{HCl}(25.2 \%$ vs $38.3 \%, \mathrm{p}=0.0039)$, calcium acetate $(3.7 \%$ vs $10.2 \%$, $\mathrm{p}=0.0046)$ or the calcimimetic cinacalcet $(0.9 \%$ to $9.4 \%$, $\mathrm{p}<0.0001)$ significantly increased from 6 months to 36 months, the use of iron supplements $(73.9 \%$ vs $64.8 \%$, $\mathrm{p}=0.049)$ or calcium carbonate $(47.4 \%$ vs $39.8 \%, \mathrm{p}=0.15)$ decreased from 6 months to 36 months.

\section{Cause of mortality}

In this survey, approximately one quarter $(25.2 \%)$ of patients died. At 12 months, 47 subjects died (8.3\%), at
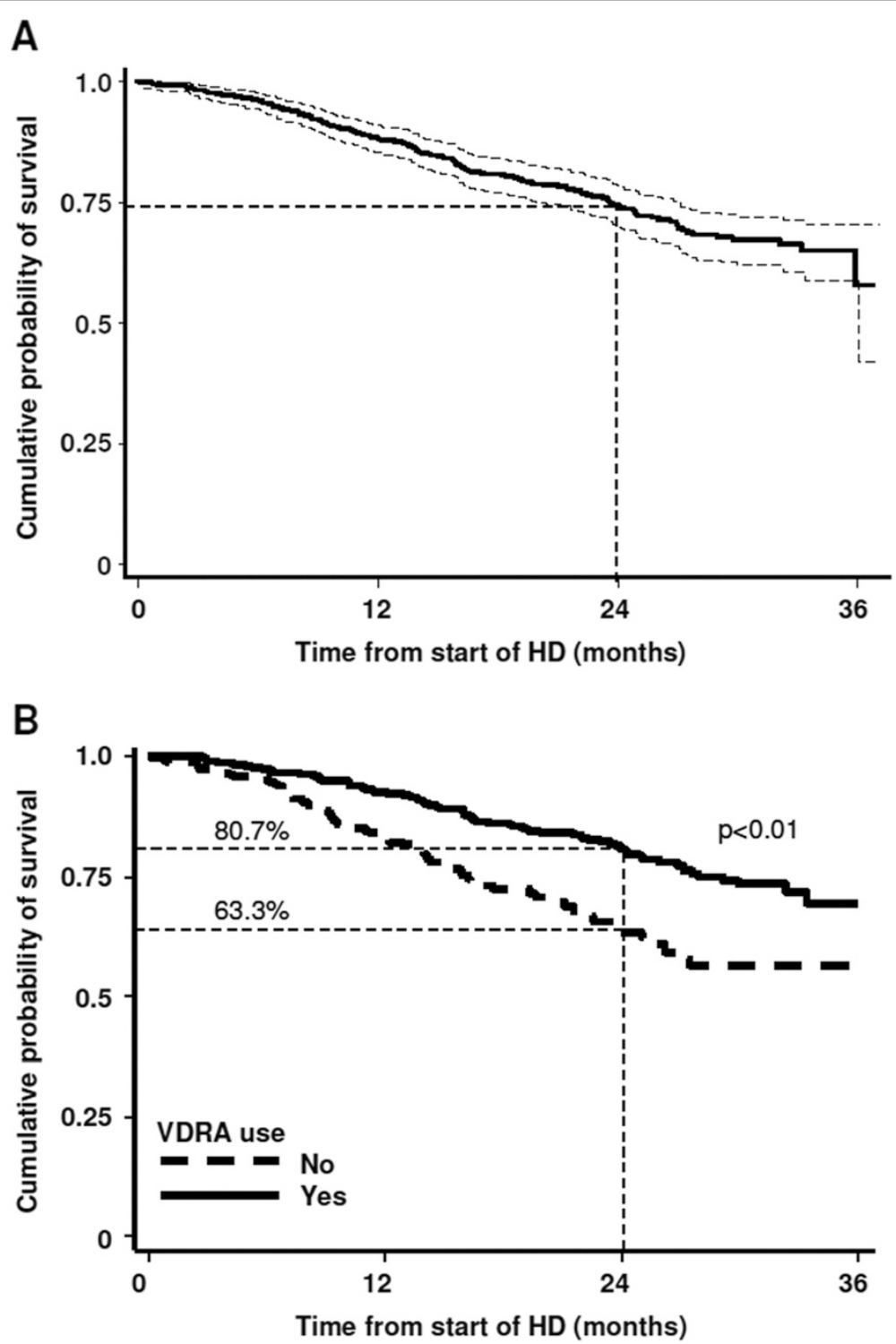

Figure 2 Kaplan Meier plots showing survival rate of all patients. The probability of surviving at least 1 year is 88.6\% (95\% Cl: 85.6-91.0), and for at least 2 years is $74.5 \%$ (95\% Cl: 70.2-78.3). Dotted lines represent upper and lower 95\% confidence intervals. A) Survival estimates (all cause mortality) for FARO-2 patients and $\mathbf{B}$ ) Kaplan Meier plot showing effect of VDRA on survival. Probability of survival at 2 years is indicated. $\mathrm{HD}=$ hemodialysis. 
18 months 44 (16.1\%) died, at 24 months 20 (19.6\%) died, at 30 months 25 (24\%) died and at 36 months 7 (25.2\%) died.The main cause of death was heart failure $25.9 \%(\mathrm{n}=37)$, followed by other unspecified causes (17.5\%), vascular causes and neoplasia (both 16.1\%), cachexia (15.4\%) and sepsis (9.1\%). The cumulative probability of survival (all-cause mortality) from start of dialysis is presented in Figure 2A. Kaplan-Meier analysis revealed that the cumulative probability of surviving at least 12 months was $88.6 \%$ (95\% CI: 85.6-91.0), at least 24 months was $74.5 \%$ (95\% CI: 70.2-78.3) (Figure 2A).

\section{Effect of VDRA on survival}

Patients who received VDRA therapy showed a significant higher survival at 24 months $(80.7 \%$; $95 \%$ CI: $75.7-$ 84.8) compared to those without VDRA treatment (63.3\%; 95\% CI: 54.8-70.7) (Figure 2B). Actually, the effect of VDRA treatment reveals that the event curves had already separated by 6 months and continued to diverge up to 2 years (Figure 2B).

\section{Effect of demographic and clinical variables on survival}

Cox proportional hazard regression models were used to estimate time to all-cause mortality hazard ratios (HR). The presence of hypertension, vascular disease, decreased hemoglobin and lack of VDRA treatment were significantly associated with an increased risk of mortality (Table 4).

Table 4 Hazard ratios of time to death (any cause), without PTH, Ca and P

\begin{tabular}{lllll}
\hline & HR & \multicolumn{2}{l}{$\mathbf{9 5 \%}$ Cl } & p-value \\
\hline Age (per 10 year increase) & 1.33 & 0.99 & 1.80 & 0.06 \\
Gender (male vs female) & 1.22 & 0.63 & 2.36 & 0.55 \\
History of hypertension (yes vs no) & 0.32 & 0.10 & 0.98 & $\mathbf{0 . 0 5}$ \\
History of dyslipidemia (yes vs no) & 0.94 & 0.42 & 2.09 & 0.88 \\
Heart disease (yes vs no) & 1.62 & 0.73 & 3.58 & 0.24 \\
Neoplasias (yes vs no) & 2.15 & 0.93 & 5.00 & 0.07 \\
Liver disease (yes vs no) & 2.04 & 0.77 & 5.41 & 0.15 \\
Vascular disease (yes vs no) & 4.60 & 2.04 & 10.38 & $\mathbf{0 . 0 0}$ \\
Treatment of diabetes (yes vs no) & 1.61 & 0.71 & 3.61 & 0.25 \\
Hemoglobin (per 1 g/dl increase) & 0.64 & 0.49 & 0.84 & $\mathbf{0 . 0 0}$ \\
Albumin (per 1 g/dl increase) & 1.12 & 0.87 & 1.45 & 0.38 \\
VDRA (no vs yes) & 2.69 & 1.38 & 5.22 & $\mathbf{0 . 0 0}$ \\
Ca-based PiB (no vs yes) & 1.11 & 0.47 & 2.67 & 0.81 \\
NoCa-based PiB (no vs yes) & 0.58 & 0.27 & 1.22 & 0.15 \\
\hline
\end{tabular}

Data presented as hazard ratios (HR) and upper and lower $95 \%$ confidence intervals $(\mathrm{Cl})$

$\mathrm{PTH}=$ parathyroid hormone; $\mathrm{P}=$ phosphorous, $\mathrm{Ca}=$ calcium; VDRA = vitamin $\mathrm{D}$ receptor activator; $\mathrm{Ca}$-based $\mathrm{PiB}=$ calcium containing phosphate binders; noCa-based $\mathrm{PiB}=$ non calcium containing phosphate binders. All variables (but age and gender) were included as time dependent covariates. Statistically significant $\mathrm{p}$-values are highlighted in bold.
Additional analysis adjusted for levels of the biochemical parameters PTH, P and Ca showed that lack of treatment with VDRA still remained significant as a predictor of mortality $(\mathrm{HR}=2.16,95 \% \mathrm{CI}: 1.09-4.30$, $\mathrm{p}=0.03)($ Table 5).

\section{Discussion}

The main finding of this analysis of the subgroup of the FARO cohort shows that VDRA treatment in incident HD patients (FARO-2 cohort) is associated with reduced overall mortality. This benefit was maintained even after adjusting for levels of the biochemical parameters PTH, $\mathrm{P}$ and $\mathrm{Ca}$.

Previous studies have consistently shown benefit in reducing overall and $\mathrm{CV}$-related mortality following VDRA use, compared to non VDRA use, [9,26-32] although studies comparing efficacy of different VDRA molecules (for example paricalcitol compared to calcitriol) on survival outcome have shown differing results [30,38,39].

What makes the FARO-2 study unique is the fact that we have examined the effect of VDRA therapy on survival in incident HD patients, the first study of this kind

\section{Table 5 Hazard ratios of time to death (any cause)}

\begin{tabular}{|c|c|c|c|c|}
\hline \multirow[b]{2}{*}{ Age (per 10 year increase) } & \multirow{2}{*}{$\frac{\mathbf{H R}}{1.35}$} & \multicolumn{2}{|c|}{$95 \% \mathrm{Cl}$} & \multirow{2}{*}{$\frac{\mathbf{p} \text {-value }}{0.06}$} \\
\hline & & 0.98 & 1.86 & \\
\hline Gender (male vs female) & 1.12 & 0.57 & 2.21 & 0.75 \\
\hline History of hypertension (yes vs no) & 0.33 & 0.10 & 1.07 & 0.07 \\
\hline History Dyslipidemia (yes vs no) & 1.03 & 0.43 & 2.45 & 0.95 \\
\hline Heart disease (yes vs no) & 1.38 & 0.60 & 3.16 & 0.45 \\
\hline Neoplasias (yes vs no) & 1.89 & 0.77 & 4.63 & 0.16 \\
\hline Liver disease (yes vs no) & 1.87 & 0.64 & 5.45 & 0.25 \\
\hline Vascular disease (yes vs no) & 4.32 & 1.90 & 9.80 & 0.00 \\
\hline Treatment of diabetes (yes vs no) & 1.72 & 0.74 & 4.01 & 0.21 \\
\hline Hemoglobin (per $1 \mathrm{~g} / \mathrm{dl}$ increase) & 0.61 & 0.46 & 0.81 & 0.00 \\
\hline Albumin (per $1 \mathrm{~g} / \mathrm{dl}$ increase) & 1.08 & 0.85 & 1.38 & 0.54 \\
\hline $\mathrm{PTH} \leq 150$ vs $150<\mathrm{PTH} \leq 300 \mathrm{pg} / \mathrm{ml}$ & 1.02 & 0.47 & 2.24 & 0.96 \\
\hline $300>$ PTH vs $150<$ PTH $\leq 300 \mathrm{pg} / \mathrm{ml}$ & 0.55 & 0.19 & 1.57 & 0.26 \\
\hline$P \leq 3.5$ vs $3.5<P \leq 5.5 \mathrm{mg} / \mathrm{dl}$ & 2.16 & 0.89 & 5.26 & 0.09 \\
\hline$P>5.5$ vs $3.5<P \leq 5.5 \mathrm{mg} / \mathrm{dl}$ & 2.63 & 1.23 & 5.60 & 0.01 \\
\hline $\mathrm{Ca} \leq 8.4$ vs $8.4<\mathrm{Ca} \leq 9.5 \mathrm{mg} / \mathrm{dl}$ & 1.88 & 0.90 & 3.92 & 0.09 \\
\hline $\mathrm{Ca}>9.5$ vs $8.4<\mathrm{Ca} \leq 9.5 \mathrm{mg} / \mathrm{dl}$ & 1.27 & 0.44 & 3.71 & 0.66 \\
\hline VDRA (no vs yes) & 2.16 & 1.09 & 4.30 & 0.03 \\
\hline Ca-based PiB (no vs yes) & 1.15 & 0.46 & 2.89 & 0.77 \\
\hline NoCa-based PiB (no vs yes) & 0.70 & 0.31 & 1.58 & 0.39 \\
\hline
\end{tabular}

Data are presented as hazard ratios (HR) and upper and lower $95 \%$ confidence intervals $(\mathrm{Cl})$. $\mathrm{PTH}=$ parathyroid hormone; $\mathrm{P}=$ phosphorous, $\mathrm{Ca}=$ calcium; VDRA $=$ vitamin $\mathrm{D}$ receptor activator; $\mathrm{Ca}$-based $\mathrm{PiB}=$ calcium containing phosphate binders; noCa-based $\mathrm{PiB}=$ non calcium containing phosphate binders. All variables (but age and gender) were included as time-dependent covariates. Statistically significant $p$-values are highlighted in bold. 
performed in Italy. Our results confirm that the main cause of death in these patients is attributed to CVrelated events $[1,2]$ and that VDRA use may play a beneficial effect on survival in HD patients [9,15,26-32]. In fact, as previously observed in the FARO study, [32] in the present analysis we have also noted that the presence of vascular disease was a significant predictor of mortality. In line with these data, vascular-related comorbidities have previously been linked to increased morbidity and mortality in HD patients [40,41]. There is no clear explanation on the precise mechanisms by which VDRA therapy might provide its cardio-vascular protective effects. To address this, the PRIMO study, a multinational double-blind randomized placebocontrolled trial, examined the effect of paricalcitol $(2 \mu \mathrm{g}$ daily) using cardiac endpoints as measures of $\mathrm{CV}$ structure and function (e.g. left ventricular mass) [42]. Although findings from this trial did not demonstrate any effect of paricalcitol on left ventricular mass or improved measures of diastolic function over 48 weeks, this study did show that paricalcitol use was associated with fewer CV-related hospitalizations, with an attenuated rise in BNP levels and decreased left atrial volume [42,43].

Collectively, these findings suggest a possible cardiovascular protective effect of VDRA and in particular of paricalcitol, though the exact mechanisms of this effect still need to be fully elucidated.

\section{Study limitations}

There are, however, some limitations of the FARO-2 study that need to be addressed. Although the number of patients at baseline was relatively large $(n=568)$, a larger sample size would have permitted additional subanalysis, accounting for drop-outs and death. The small sample size also precluded the possibility of evaluating the possibility of any potential dose-related effect of VDRA therapy on overall survival. In addition, although some classical factors did not attain statistical significance, possibly again attributed to the low sample number, several other clinical characteristics emerged as risk factors for survival, corroborating other studies $[32,40,41]$. Furthermore it was retrospective and observational design. On the other hand, there are several strengths of the FARO-2 study worth noting. First, it is based on an observation over a long period of time (36 months) of incident CKD patients undergoing dialysis treatment. Second, it was a multicentric study with the contribution of many centers distributed around Italy and therefore, its findings can be considered well representative of the entire Italian dialysis population. Furthermore, no studies are available reporting on the effect of VDRA therapy on mortality data on incident HD Italian population.

\section{Conclusions}

In summary, the present study suggests that VDRAs may play an important role in decreasing all-cause and cardiovascular mortality in incident HD patients. However, considering the inherent limitations of retrospective analyses, the benefit of VDRA treatment on survival in HD patients still remains to be confirmed in large prospective randomized clinical trials.

\section{Competing interests}

The authors declare that they have no competing interests.

\section{Authors' contributions}

PM, MC, DB, GC, FM, AMC, UCP and SM participated in the design of the study and interpretation of data. VF and GG participated in interpretation of data and writing of the manuscript. All authors were involved in drafting the manuscript and read and approved the final manuscript.

\section{Acknowledgements}

The authors would like to thank the FARO study group: Piergiorgio Bolasco (Quartu S. Elena), Mario Bonomini (Chieti), Giovanni Cancarini (Brescia), Maria Rosa Caruso (Bergamo), Marina Di Luca (Pesaro), Loreto Gesualdo (Bari), Cosimo Lodeserto (Taranto), Annalisa Lucchesi (Livorno), Martino Marangella (Torino), Massimo Morosetti (Ostia Lido), Francesco Quarello (Torino), Giuseppe Rombolà (La Spezia), Sergio Stefoni (Bologna). We would also like to thank Dr Colin Gerard Egan (Primula Multimedia SRL, Pisa Italy) for medical writing assistance (funded by AbbVie) and INFORMA srl for the statistical analysis.

\section{Disclosures}

Piergiorgio Messa - FARO Steering Committee. Lecture honoraria from Janssen Cilag, Amgen.

Mario Cozzolino - FARO Steering Committee. Lecture honoraria from Abbott, Shire, Amgen, Genzyme, Roche.

Diego Brancaccio - FARO Steering Committee. Consultant for Abbott; lecture honoraria from GSK, Amgen and Shire.

Giuseppe Cannella - FARO Steering Committee. Lecture honoraria from Abbott.

Fabio Malberti - Lecture honoraria from Amgen.

Anna Maria Costanzo - Abbvie Italy Head Medical Affairs SH Umberto di Luzio Paparatti - Abbvie Italy Affiliate Medical Director Vincenzo Festa - AbbVie Italy Medical Manager

Giuliana Gualberti - AbbVie Italy Biometrics and Compliance Manager Sandro Mazzaferro - FARO Steering Committee. Lecture honoraria from Shire and Amgen.

This study was sponsored by AbbVie. AbbVie contributed to the study design, research, and interpretation of data, writing, reviewing, and approving the publication.

\section{Author details}

'Nephrology, Dialysis and renal Transplant, Fondazione Ca' Granda IRCCS-Policlinico, Milan, Italy. ${ }^{2}$ Department of Health Sciences, University of Milan - Renal Division - San Paolo Hospital, Milan, Italy. ${ }^{3}$ Dialysis Unit, "Simone Martini", Milan, Italy. ${ }^{4}$ Department of Nephrology, San Martino Hospital, Genoa, Italy. ${ }^{5}$ Divisione di Nefrologia e Dialisi, Azienda Ospedaliera Istituti Ospitalieri di Cremona, Cremona, Italy. ${ }^{6}$ AbbVie Italy, Campoverde, Latina, Italy. ${ }^{7}$ Dipartimento di Scienze Cardiovascolari Respiratorie Nefrologiche e Geriatriche, Sapienza Università di Roma, Roma, Italy.

Received: 12 February 2014 Accepted: 25 January 2015

Published online: 06 February 2015

\section{References}

1. Foley RN, Parfrey PS, Sarnak MJ. Clinical epidemiology of cardiovascular disease in chronic renal disease. Am J Kidney Dis. 1998;32 Suppl 3:S112-9.

2. Iseki K, Shinzato T, Nagura Y, Akiba T. Factors influencing long-term survival in patients on chronic dialysis. Clin Exp Nephrol. 2004;8:89-97. 
3. Block GA, Hulbert-Shearon TE, Levin NW, Port FK. Association of serum phosphorus and calcium $x$ phosphate product with mortality risk in chronic hemodialysis patients: a national study. Am J Kidney Dis. 1998;31:607-17.

4. Stevens LA, Djurdjev O, Cardew S, Cameron EC, Levin A. Calcium, phosphate, and parathyroid hormone levels in combination and as a function of dialysis duration predict mortality: evidence for the complexity of the association between mineral metabolism and outcomes. J Am Soc Nephrol. 2004:15:770-9.

5. Block GA, Klassen PS, Lazarus JM, Ofsthun N, Lowrie EG, Chertow GM. Mineral metabolism, mortality, and morbidity in maintenance hemodialysis. J Am Soc Nephrol. 2004;15:2208-18.

6. Slinin Y, Foley RN, Collins AJ. Calcium, phosphorus, parathyroid hormone, and cardiovascular disease in hemodialysis patients: the USRDS waves 1, 3, and 4 study. J Am Soc Nephrol. 2005;16:1788-93.

7. Kestenbaum B, Sampson JN, Rudser KD, Patterson DJ, Seliger SL, Young B, et al. Serum phosphate levels and mortality risk among people with chronic kidney disease. J Am Soc Nephrol. 2005;16:520-8.

8. Young EW, Albert JM, Satayathum S, Goodkin DA, Pisoni RL, Akiba T, et al. Predictors and consequences of altered mineral metabolism: the dialysis outcomes and practice patterns study. Kidney Int. 2005;67:1179-87.

9. Kalantar-Zadeh K, Kuwae N, Regidor DL, Kovesdy CP, Kilpatrick RD, Shinaberger CS, et al. Survival predictability of time-varying indicators of bone disease in maintenance hemodialysis patients. Kidney Int. 2006;70:771-80.

10. Wald R, Sarnak MJ, Tighiouart H, Cheung AK, Levey AS, Eknoyan G, et al. Disordered mineral metabolism in hemodialysis patients: an analysis of cumulative effects in the Hemodialysis (HEMO) Study. Am J Kidney Dis. 2008;52:531-40

11. Tentori F, Blayney MJ, Albert JM, Gillespie BW, Kerr PG, Bommer J, et al. Mortality risk for dialysis patients with different levels of serum calcium, phosphorus, and PTH: the dialysis outcomes and practice patterns study (DOPPS). Am J Kidney Dis. 2008;52:519-30.

12. Floege J, Kim J, Ireland E, Chazot C, Drueke T, de Francisco A, et al. Serum iPTH, calcium and phosphate, and the risk of mortality in a European haemodialysis population. Nephrol Dial Transplant. 2011;26:1948-55.

13. Nakai S, Akiba T, Kazama J, Yokoyama K, Fukagawa M, Tominaga Y, et al. Patient registration committee of the Japanese society for dialysis therapy, Tokyo, Japan: effects of serum calcium, phosphorous, and intact parathyroid hormone levels on survival in chronic hemodialysis patients in Japan. Ther Apher Dial. 2010;12:49-54.

14. Naves-Díaz M, Passlick-Deetjen J, Guinsburg A, Marelli C, Fernández-Martín JL, Rodríguez-Puyol D, et al. Calcium, phosphorus, PTH and death rates in a large sample of dialysis patients from Latin America the CORES study. Nephrol Dial Transplant. 2011;26:1938-47.

15. Cozzolino M, Brancaccio D, Cannella G, Messa P, Gesualdo L, Marangella M, et al. VDRA therapy is associated with improved survival in dialysis patients with serum intact PTH $\leq 150 \mathrm{pg} / \mathrm{mL}$ : results of the Italian FARO Survey. Nephrol Dial Transplant. 2012;27:3588-94.

16. Martin KJ, Gonzalez EA. Metabolic bone disease in chronic kidney disease. J Am Soc Nephrol. 2007;18:875-85.

17. Levin A, Bakris GL, Molitch M, Smulders M, Tian J, Williams LA, et al. Prevalence of abnormal serum vitamin D, PTH, calcium, and phosphorus in patients with chronic kidney disease: results of the study to evaluate early kidney disease. Kidney Int. 2007;71:31-8.

18. Wolf M, Thadhani R. Vitamin D in patients with renal failure: a summary of observational mortality studies and steps moving forward. J Steroid Biochem Mol Biol. 2007;103:487-90.

19. Salusky IB, Goodman WG. Cardiovascular calcification in end-stage renal disease. Nephrol Dial Transplant. 2002;17:336-9.

20. Wolisi GO, Moe SM. The role of vitamin D in vascular calcification in chronic kidney disease. Semin Dial. 2005;18:307-14.

21. Brown AJ, Slatopolsky E. Drug insight: vitamin D analogs in the treatment of secondary hyperparathyroidism in patients with chronic kidney disease. Nat Clin Pract Endocrinol Metab. 2007;3:134-44.

22. Ronco C, Cozzolino M. Mineral metabolism abnormalities and vitamin D receptor activation in cardiorenal syndromes. Heart Fail Rev. 2012;17:211-20.

23. Khan S. Vitamin D deficiency and secondary hyperparathyroidism among patients with chronic kidney disease. Am J Med Sci. 2007;333:201-7.

24. Lund RJ, Andress DL, Amdahl M, Williams LA, Heaney RP. Differential effects of paricalcitol and calcitriol on intestinal calcium absorption in hemodialysis patients. Am J Nephrol. 2010;31:165-70.
25. Greenbaum LA, Benador N, Goldstein SL, Paredes A, Melnick JZ, Mattingly S, et al. Intravenous paricalcitol for treatment of secondary hyperparathyroidism in children on hemodialysis. Am J Kidney Dis. 2007;49:814-23.

26. Teng M, Wolf M, Lowrie E, Ofsthun N, Lazarus JM, Thadhani R. Survival of patients undergoing hemodialysis with paricalcitol or calcitriol therapy. N Engl J Med. 2003;349:446-56.

27. Teng $M$, Wolf $M$, Ofsthun MN, Lazarus JM, Hernán MA, Camargo Jr CA, et al. Activated injectable vitamin D and hemodialysis survival: a historical cohort study. J Am Soc Nephrol. 2005;16:1115-25.

28. Naves-Díaz M, Alvarez-Hernández D, Passlick-Deetjen J, Guinsburg A, Marelli C, Rodriguez-Puyol D, et al. Oral active vitamin D is associated with improved survival in hemodialysis patients. Kidney Int. 2008;74:1070-8.

29. Wolf M, Betancourt J, Chang Y, Shah A, Teng M, Tamez H, et al. Impact of activated vitamin $D$ and race on survival among hemodialysis patients. J Am Soc Nephrol. 2008;19:1379-88.

30. Tentori F, Albert JM, Young EW, Blayney MJ, Robinson BM, Pisoni RL, et al. The survival advantage for HD patients taking vitamin $D$ is questioned: findings from the dialysis outcomes and practice patterns study. Nephrol Dial Transplant. 2009;24:963-72.

31. Ogawa T, Kyono A, Sato M, Sugimoto H, Otsuka K, Nitta K. Vitamin D receptor agonist supplementation and suppression of inflammation may have advantage for all-cause mortality in hemodialysis patients. Clin Exp Nephrol. 2012;16:779-85.

32. Brancaccio D, Cozzolino M, Cannella G, Messa P, Bonomini M, Cancarini G, et al. Secondary hyperparathyroidism in chronic dialysis patients: results of the Italian FARO survey on treatment and mortality. Blood Purif. 2011;32:124-32.

33. Iseki K, Tozawa M, Takishita S. Effect of the duration of dialysis on survival in a cohort of chronic hemodialysis patients. Nephrol Dial Transplant. 2003;18:782-7.

34. Mazzaferro S, Brancaccio D, Messa P, Andreucci VE, Bellinghieri G, Bigazzi R, et al. Management of secondary hyperparathyroidism in Italy: results of the Italian FARO survey. J Nephrol. 2011;24:225-35.

35. National Kidney Foundation. KDOQI clinical practice guidelines for bone metabolism and disease in chronic kidney disease. Am J Kidney Dis. 2003;42:S1-202.

36. Cozzolino M, Messa P, Brancaccio D, Cannella G, Mazzaferro $S$ and the FARO-2 Study Group: Achievement of the NKF/K-DOQI recommended target values for bone and mineral metabolism in incident haemodialysis patients: results of the FARO-2 cohort. Abstracts of the 49th ERA-EDTA (European Renal Association - European Dialysis and Transplant Association) Congress. May 24-27, 2012. Paris, France. Nephrol Dial Transplant 27 Suppl 2:ii1-536. Abstract number 565, 2012

37. Moeschberger ML, Klein JP. Survival analysis: techniques for censored and truncated data. 2nd ed. Springer Science and Business Media, Inc: New York, NY; 2003.

38. Tentori F, Hunt WC, Stidley CA, Rohrscheib MR, Bedrick EJ, Meyer KB, et al. Mortality risk among hemodialysis patients receiving different vitamin $D$ analogs. Kidney Int. 2006;70:1858-65.

39. Dobrez DG, Mathes A, Amdahl M, Marx SE, Melnick JZ, Sprague SM. Paricalcitol-treated patients experience improved hospitalization outcomes compared with calcitriol-treated patients in real-world clinical settings. Nephrol Dial Transplant. 2004;19:1174-81.

40. Longenecker JC, Coresh J, Powe NR, Levey AS, Fink NE, Martin A, et al. Traditional cardiovascular disease risk factors in dialysis patients compared with the general population: the CHOICE Study. J Am Soc Nephrol. 2002:13:1918-27.

41. Miguel SB, Miguel JB, Velarde LG, Sampaio Ede A, Matos JP, Lugon JR. Prevalence and correlates of vascular disease at ultrasound examination in patients on hemodialysis. Arq Bras Cardiol. 2011;96:260-5.

42. Thadhani R, Appelbaum E, Pritchett Y, Chang Y, Wenger J, Tamez H, et al. Vitamin D therapy and cardiac structure and function in patients with chronic kidney disease: the PRIMO randomized controlled trial. JAMA. 2012;15(307):674-84.

43. Tamez H, Zoccali C, Packham D, Wenger J, Bhan I, Appelbaum E, et al. Vitamin $D$ reduces left atrial volume in patients with left ventricular hypertrophy and chronic kidney disease. Am Heart J. 2012;164:902-909.e2. 